\begin{tabular}{|c|c|}
\hline UÁQUIRI & PPG \\
\hline & Revista do Programa de Pós-Graduação em Geografia \\
UÁQUIRI - PPGGEO, v. 03, n. 01, p. 95-104, ano 2021 & \\
Home page: https://periodicos.ufac.br/index.php/Uaquiri & ISSN 2675-4088 \\
\hline
\end{tabular}

\title{
(RELATOS DE EXPERIENCIAS) O JOGO, A GAMIFICAÇÃO E O LÚDICO NO ENSINO DE GEOGRAFIA DURANTE A PANDEMIA DA COVID-19
}

\author{
Janiara Almeida Pinheiro Lima ${ }^{*}$ \\ ORCID: https://orcid.org/0000-0001-5183-7693
}

\begin{abstract}
${ }^{1}$ Mestra em Geografia - PPGEO - UFPE; Professora de Geografia efetiva da Rede Municipal de Ensino do Recife e da Rede Estadual de Ensino de Pernambuco; Membro do Grupo de pesquisa em Ensino de Geografia e Construção de Conceitos Geográficos - GEOCONCEITO/UFPE; Membro do Laboratório de Pesquisa e Inovação - LEGEP/UFPE; Recife, Pernambuco, Brasil

*janiara8890@gmail.com
Aprovado como destaque no I Simpósio Nacional de Metodologias Ativas na Educação Profissional e Tecnológica (I SinmaEPT).
Publicado em: 30/07/2021
DOI: https://doi.org/10.47418/uaquiri.vol3.n1.2021.5136

\begin{abstract}
RESUMO
O presente trabalho é referente ao uso de jogos didáticos, construídos a partir da plataforma digital Wordwall, como recurso didático nas aulas remotas de Geografia, durante o ano de 2020, correspondente ao período pandêmico, para turmas de $7^{\circ}$ ano do Ensino Fundamental - Anos finais, da Escola Municipal São Cristóvão, localizada na periferia da cidade do Recife-PE. Nesse trabalho procurou-se explorar o lúdico através dos jogos para alcançar o interesse dos estudantes pelos objetos de aprendizagem da Geografia, dispostos no currículo da Rede Municipal, por meio da Aprendizagem Baseada em Jogos e da Gamificação.
\end{abstract}

Palavras-chave: Jogos; Gamificação; Lúdico; Geografia; Ensino.

\section{GAME, GAMIFICATION AND PLAYER IN TEACHING GEOGRAPHY DURING THE COVID- 19 PANDEMIC}

\section{ABSTRACT}

The present work refers to the use of educational games, built from the digital platform Wordwall, as a teaching resource in remote Geography classes, during the year 2020, corresponding to the pandemic period, for classes of the 7th year of Elementary School - Final years, from São Cristóvão Municipal School, located on the outskirts of the city of Recife-PE. In this work we tried to explore the playfulness through games to reach the students' interest in the objects of learning of Geography, arranged in the curriculum of the Municipal Network, through Learning Based on Games and Gamification.

Keywords: Games; Gamification; Ludic; Geography; Teaching. 


\section{JUEGO, GAMIFICACIÓN Y JUGADOR EN LA ENSEÑANZA DE GEOGRAFÍA DURANTE LA PANDEMIA DEL COVID-19}

\section{RESUMEN}

El presente trabajo se refiere al uso de juegos educativos, construidos a partir de la plataforma digital Wordwall, como recurso didáctico en clases de Geografía a distancia, durante el año 2020, correspondiente al período pandémico, para las clases del $7^{\circ}$ año de Primaria - Últimos años. , de la Escuela Municipal São Cristóvão, ubicada en las afueras de la ciudad de Recife-PE. En este trabajo se intentó explorar la lúdica a través de juegos para llegar al interés de los estudiantes por los objetos de aprendizaje de la Geografía, dispuestos en el plan de estudios de la Red Municipal, a través del Aprendizaje Basado en Juegos y la Gamificación.

Palabras clave: Juegos; Gamificación; Lúdico; Geografía; Enseñando.

\section{INTRODUÇÃO}

Ensinar Geografia no contexto de pandemia tem sido um grande desafio. Uma vez que, diante das dificuldades inerentes ao processo de ensino-aprendizagem, a mudança de ambiente escolar, do convívio presencial para o convívio virtual, mudou também a percepção de estudantes e professores sobre como utilizar as tecnologias digitais de informação e comunicação (TDIC’s) para fins educacionais.

A Geografia enquanto ciência que estuda o espaço geográfico e suas espacialidades, insere-se no contexto escolar como um arcabouço de saberes que proporciona o entendimento do mundo e das cotidianidades (CAVALCANTI, 2014; CALLAI, 2015). Mais do que nunca, foi preciso, diante da pandemia provocar-nos a entender o novo contexto cotidiano em que fomos inseridos diante da crise sanitária provocada pelo Sars-CoV-2.

Assim, as escolas e suas comunidades empenharam-se para superar os desafios que esse contexto ambiental nos imputou e, mais do que nunca, professores e estudantes puseram-se a aprender novas maneiras de ensinar e aprender, ou adaptar a velha maneira de fazer a educação

funcionar, em espaços escolares inovadores e criativos, para além dos muros da escola (LIMA, 2020).

Nas aulas de Geografia, para estudantes do $7^{\circ}$ ano do Ensino Fundamental - Anos Finais, da Escola Municipal São Cristóvão, foram elencadas como recursos didáticos os jogos produzidos na plataforma digital wordwall, a fim de gamificar as aulas e transformar as aulas remotas de Geografia em espaços de aprendizagem ativa e significativa (MOREIRA, 1999), aos estudantes que tinham acesso a elas.

Considerando que a gamificação representa a "[...] utilização da mecânica dos games, em cenários non games, criando espaços de aprendizagem mediados pelo desafio, pelo prazer 
e entretenimento" (ALVES et al., 2016, p. 76), buscou-se fazer uso desse conceito e pô-lo em prática.

Como objetivo geral deste trabalho enunciou-se Ensinar Geografia de forma lúdica através do uso de jogos e da Gamificação. E decorrentes deste, como objetivos específicos pode-se enumerar: Promover a aprendizagem por meio de jogos; criar espaços participativos de ensino da Geografia; Engajar os estudantes na participação das aulas de Geografia.

Nesse contexto, a aprendizagem baseada em jogos procurou proporcionar um cenário de aprendizagem divertido, atrativo e participativo, onde os estudantes puderam interagir nas aulas de Geografia, construindo coletivamente seus saberes, mesmo diante de um cenário desafiador e a longo prazo cansativo/ repetitivo como das aulas remotas.

Daí, usar a gamificação e a ludicidade como ferramenta didática de engajamento dos estudantes nas aulas de Geografia foi uma maneira de tornar diferente e atraentes as aulas online e motivar os estudantes a não abandonarem a vida escolar, mesmo diante das dificuldades.

\section{FUNDAMENTANDO E EXPERIENCIANDO A ENSINAGEM DA GEOGRAFIA COM OS JOGOS, A GAMIFICAÇÃO E O LÚDICO NO ENSINO FUNDAMENTAL - ANOS FINAIS}

Este trabalho fundamenta-se na Gamificação e seus benefícios educacionais conforme Alves et al. (2014), na Gamificação como metodologia ativa de acordo com Bacich e Moran (2018) e Moraes e Castellar (2018), no jogo como ferramenta didática como enuncia Mendonça (2018), na aprendizagem baseada em jogos de acordo com Sena et al. (2016) e no lúdico no ensino e aprendizagem de Geografia tomando como base Luckesi (1994), Santos (2000) e Silva (2016).

Desse modo, é mister compreender as nuances que embasaram esse trabalho a fim de compreender o porquê da prática docente vivenciada, uma vez que, enquanto professores, também somos pesquisadores de nossa prática e a fundamentamos teoricamente com base nas pesquisas realizadas sobre o que pretendemos fazer e o que fazemos na sala de aula, o que nos permite buscar novos caminhos para proporcionar aos estudantes novos espaços de aprendizagem.

Portanto, ao pesquisar sobre a Gamificação é sobremaneira importante o que nos enuncia Alves et al. (2016) quando aponta que a Gamificação colabora, nos distintos espaços educacionais, para a aquisição de habilidades diversas, dentre elas, as cognitivas e sociais. 
Bacich e Moran (2018) por sua vez, reiteram que as metodologias ativas elevam as relações entre estudantes e professores a um patamar de cooperação e integração. Nessa mesma linha de pensamento, Moraes e Castellar (2018) enunciam que o ensino de Geografia por meio de metodologias ativas, expressas em jogos, colaboram para estimular a construção de conceitos geográficos durante o processo de ensino e aprendizagem.

Dialogando com os autores, entende-se que ensinar Geografia pode ser divertido e a criatividade ao apresentar os conteúdos, conceitos, temas e objetos de aprendizagem da Geografia pode fazer diferença no estímulo aos estudantes, pois, criar uma atmosfera de acolhimento e divertimento, por meio de metodologias e cenários educativos que despertem a curiosidade dos estudantes é um grande passo para quererem aprender o que estão sendo provocados.

Os jogos, colaboram para essa "curiosidade epistemológica" (FREIRE, 2007). Sena et al. (2016, p.2) reforça ainda que "Os jogos trazem em si uma infinidade de conceitos que estimulam a aprendizagem, pois, permitem a interação com o meio e a construção coletiva de conceitos e experiências, bem como a geração de conhecimento".

Nesse contexto, diante das mudanças bruscas de espaços de aprendizagem imputadas pela pandemia, a necessidade de inovar e buscar caminhos para alavancar os novos espaços de aprendizagem, de forma a serem atrativos aos estudantes, tem impulsionado os docentes à apropriação de ferramentas digitais para fins educacionais e alertam para urgência de dialogar com as TDIC's mais intimamente, à medida que também expõem nossas fragilidades em relação a elas.

Mendonça (2018) chama atenção sobre um importante aspecto, ela elucida que o uso de tecnologias digitais no processo de ensino-aprendizagem desdobra-se em aprendizagem significativa para os estudantes. Sendo, portanto, coerente conhecer e usar - se possível - tais tecnologias.

É por meio das ferramentas digitais que muitos docentes têm conseguido manter viva a sala de aula, embora sejam inegáveis as diferentes realidades e contextos socioespaciais que despontam país afora. Contudo, são as tecnologias digitais e a internet que ainda tem feito a distância entre docentes e discentes se encurtar frente a um contexto de incertezas. Elas também representam um caminho para explorar o lúdico e junto a ele somam-se as oportunidades de construção do saber.

Luckesi (1994, p.115) corrobora com esse diálogo quando nos provoca a refletir sobre o lúdico, ao mencionar sua importância na educação escolar como possibilidade do estudante 
aprender de maneira contextualizada e divertida, para ele "O lúdico significa a construção criativa da vida, enquanto ela é vivida". O que reforça a ideia de Silva (2016) quando enuncia que "O lúdico é um instrumento que contribui positivamente na aquisição de diversas habilidades do sujeito, sendo ainda capaz de promover o aprendizado da criança de maneira prazerosa principalmente em seu âmbito escolar".

Santos (2000, p. 60) contribui para a discussão quando afirma que "a ludicidade é uma necessidade do ser humano em qualquer idade e não pode ser vista apenas como diversão", pois que aprender de forma divertida é apenas mais uma forma de aprender. O que chama a atenção para a importância do lúdico no contexto escolar e sua relevância frente as metodologias que podem ser aplicadas em diferentes etapas do ensino.

Contextualizando a realidade pandêmica em que estamos inseridos e frente aos tantos desafios que ainda estão por vir, mitigar as distâncias, as incertezas, as angustias, o sofrimento por meio de uma sala de aula lúdica é um amalgama tanto para discentes quanto para docentes, pois que, com essa forma de interação, as relações passam a ganhar confiança e trazer aconchego, para além do ensinar e aprender os conteúdos da ciência geográfica, ao mesmo tempo em que promove a construção de valores e senso crítico sobre que se pretende aprender com esta ciência.

\section{METODOLOGIA}

A metodologia utilizada nesse trabalho consistiu de procedimentos que inseriram a gamificação como mecanismo para promover o ensino de Geografia de forma lúdica e significativa em aulas para turmas do $7^{\circ}$ ano do Ensino Fundamental da Escola Municipal São Cristóvão, durante o período pandêmico.

As aulas em formato remoto foram dinamizadas pelo uso da ferramenta didática on-line chamada wordwall, disponível no site wordwall.net (Figura 1), que permite ao docente usar jogos já disponíveis na plataforma ou criar jogos que condigam com a realidade em que está inserido. Neste caso, foram criados jogos para abordar os objetos de aprendizagem e conteúdos curriculares da Geografia do $7^{\circ}$ ano previstos no currículo da Política de Ensino da Rede Municipal do Recife. 


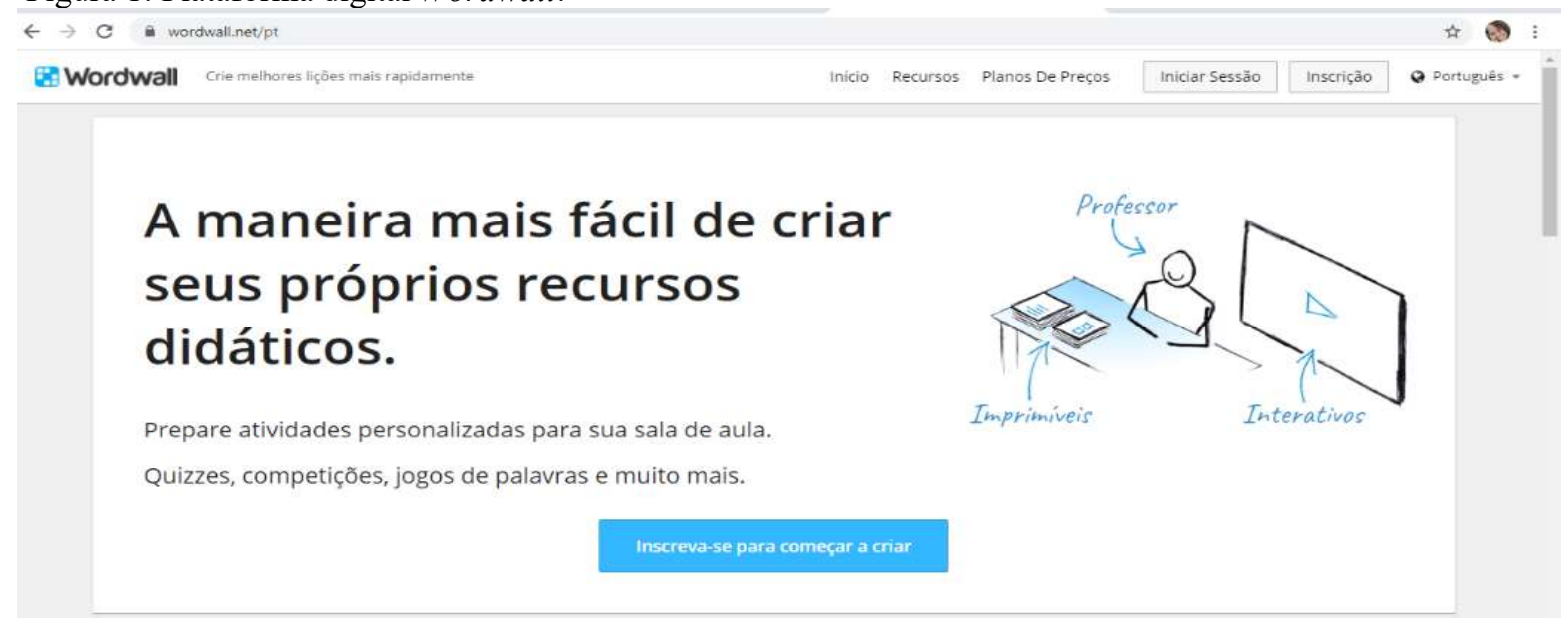

Fonte: Wordwall, 2020.

Dessa forma, durante as aulas de Geografia dos $7^{\circ} \mathrm{s}$ anos B, C e D, realizadas nas tardes de quinta e sexta-feira, de forma on-line, pelo Google Meet, conceitos de Geografia foram inseridos por meio de jogos elaborados conforme os objetos de aprendizagem da semana em questão e os planos de ensino disponíveis no site UNIREC ${ }^{1}$.

Os tipos de jogos mais utilizados durante as aulas remotas de Geografia foram: caçapalavras, quiz, anagrama, palavras-cruzadas e combinar, escolhidos dentre os modelos gratuitos disponíveis na plataforma. A Figura 2 ilustra o início de um dos jogos elaborados para as referidas turmas.

Figura 2: Layout inicial do caça-palavras sobre a agricultura familiar

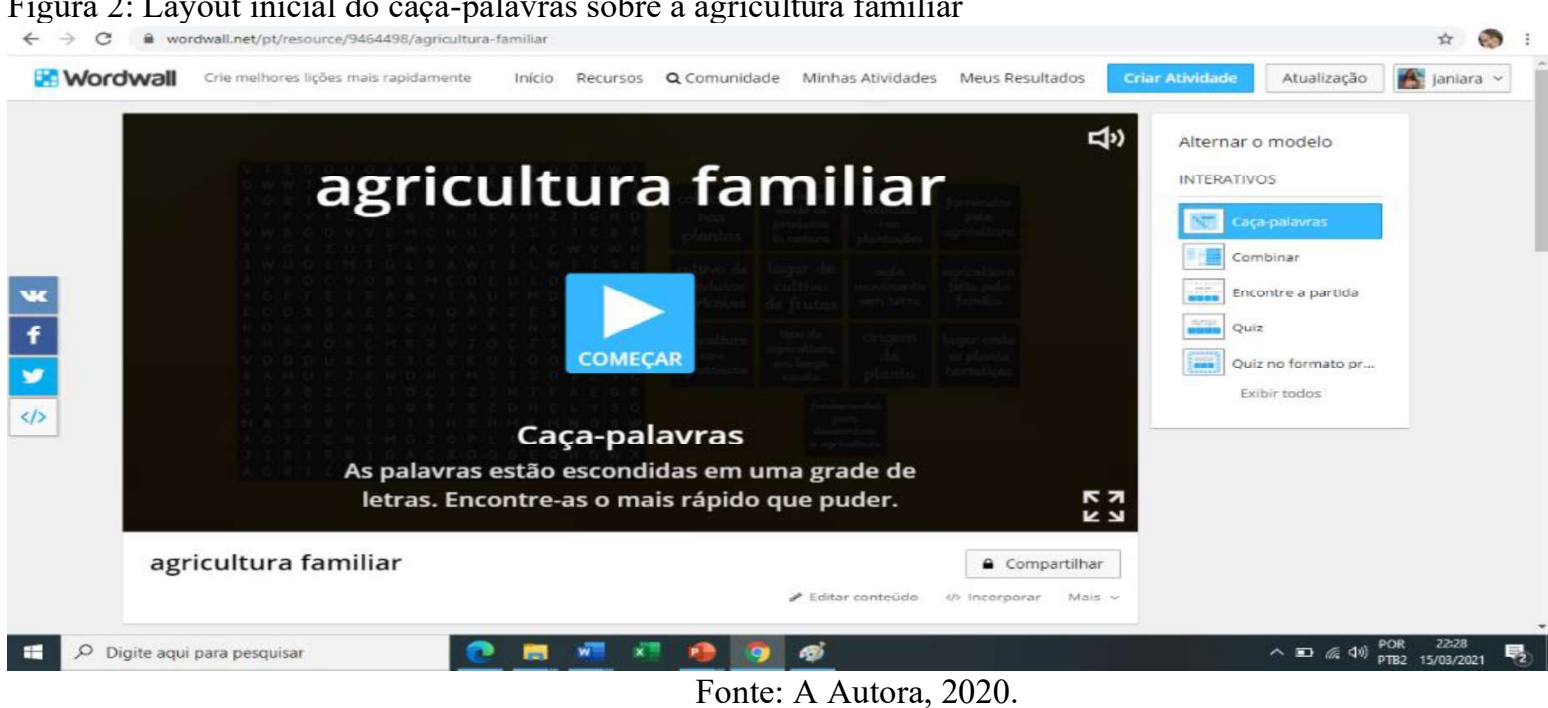

\footnotetext{
${ }^{1}$ A UNIREC é a plataforma digital que a Secretaria de Educação do Recife utiliza para promover cursos para professores e estudantes. Foi nesta Plataforma que os planos de estudos semanais elaborados pelos técnicos da PCR foram disponibilizados como um currículo a ser utilizado pelo professor durante o período de aulas remotas. Podendo ser adaptados aos contextos socio estruturais de cada sala de aula, como foi realizado neste trabalho. Neste mesmo site, também são disponibilizadas, na parte do estudante, atividades, textos, mapas mentais. Além de espaços de interação professor-aluno por meio de chats e fóruns.
} 
Conforme demonstra o caça-palavras (Figuras 3 e 4), é um jogo onde as palavras devem ser decifradas em meio as letras embaralhadas e depois os estudantes precisavam fazer a correspondência da palavra encontrada com a sua característica correspondente.

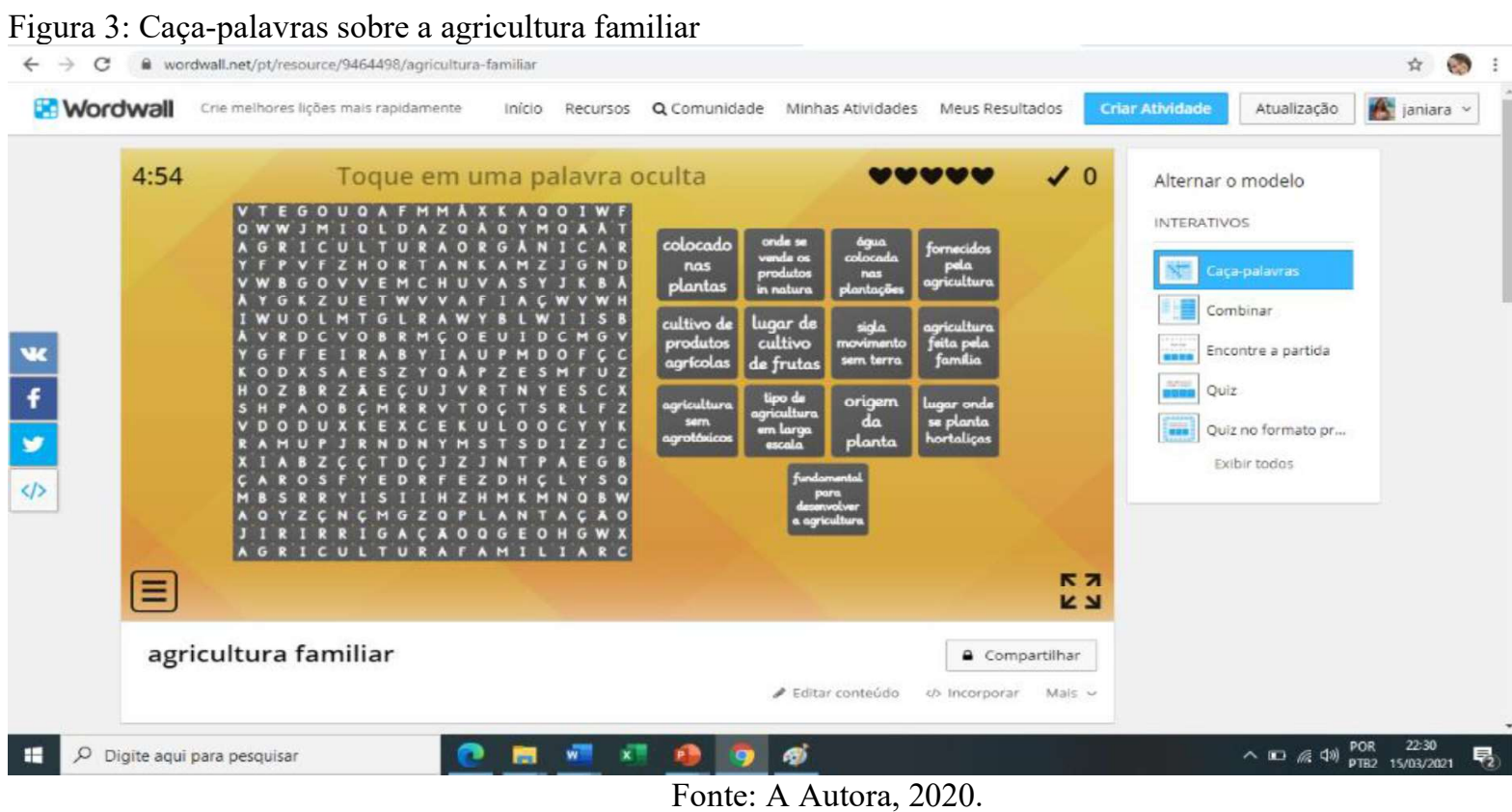

Figura 4: Caça-palavras sobre a agricultura familiar e correspondência palavra-característica.

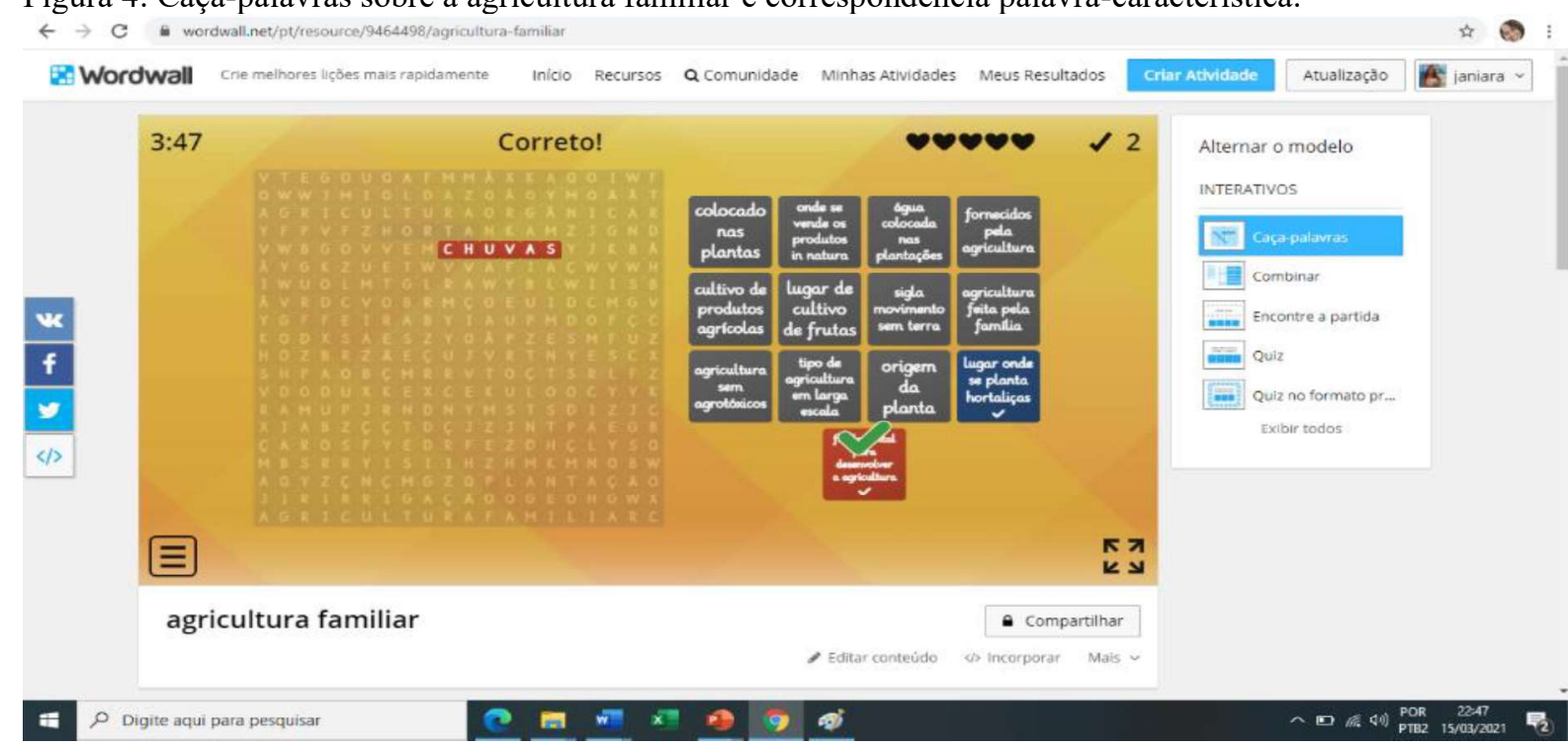

Fonte: A Autora, 2020.

Como pode ser observado, foram elencadas treze palavras acerca do tema agricultura familiar. Foram elas: adubo, irrigação, feira, alimentos, horta, chuvas, agricultura orgânica, agricultura familiar, plantação, sementes, pomar, MST, agricultura comercial. A escolha das palavras fez referência a um dos conteúdos vivenciados que foi a Agricultura e os tipos de agricultura. 
Assim, ao abordar o contexto da agricultura familiar, numa tentativa de aproximar o conteúdo a realidade dos estudantes, buscou-se elencar palavras relacionadas a esse tipo de agricultura e suas características. Ao mesmo tempo, nessa contextualização, construíram-se saberes sobre a temática da agricultura como um todo e oralmente pode-se relacionar e desvelar os tipos de agricultura e suas características operacionais e implicações para a vida em sociedade e correspondência socioambiental.

O jogo tinha um tempo de 5 min, para ser realizado, daí a importância do trabalho em equipe para poder vencer o tempo. Não houve competição entre os estudantes e sim deles com o tempo. Para cada jogo, também se tinha cinco vidas, que eram perdidas à medida que se escolhia uma letra que não correspondia a nenhuma das palavras indicadas, fazendo com que os estudantes ficassem atentos para indicar a marcação correta das palavras.

\section{RESULTADOS E DISCUSSÕES}

Sendo o jogo um elemento imbuído de ludicidade e que atrai a atenção dos estudantes, usar de elementos do jogo e até mesmo criar jogos para contextualizar ou desvelar conceitos geográficos com estudantes de Ensino Fundamental - Anos Finais, em tempos de pandemia de Covid-19, é estratégico.

Tomando como base os autores que inspiraram essa ação pedagógica, os resultados esperados com a utilização dos jogos nas aulas de Geografia, eram o maior engajamento estudantil, maior motivação em participar das aulas, aprendizagem significativa, participativa e colaborativa acerca dos conteúdos e objetos de aprendizagem, desenvolvimento de valores e construção de senso crítico.

Desse modo, o lúdico e a Gamificação realizada por meio dos jogos e elementos dos jogos, como as perguntas e respostas problematizadoras durante as aulas, e o próprio ato de jogar em equipe, retrucar as suas respostas, refletir sobre os conceitos, buscou proporcionar espaços de aprendizagem participativos e divertidos.

Nesse contexto, um dos principais resultados alcançados foi a participação dos estudantes oralmente durante a aula, o engajamento dos mesmos em compreender os conteúdos e decifrar os enigmas, expressar os conceitos geográficos inseridos nos jogos vivenciados, a alegria de conseguir acertar a tarefa junto com os colegas, o sentimento de motivação, cooperação e de conseguir superar desafios.

Outro ponto a ser ressaltado é que nas aulas que envolviam jogos os pais dos estudantes, que acompanhavam as aulas, por vezes, também se motivavam e acabavam participando das 
aulas junto com seus filhos. O que estabeleceu na relação de pais e filhos o estreitamento de laços afetivos e o compromisso com a participação da vida escolar dos estudantes. Uma vez que, diante das dificuldades de acesso à tecnologia digital, muitas vezes, um único aparelho celular passou a ter uso comunitário nas casas e nas famílias.

É fato que, infelizmente, nem todos os estudantes tiveram a oportunidade de se inserir no contexto das aulas remotas, mesmo com a disponibilidade da internet oferecida pela Prefeitura do Recife por meio de chip de celular com pacote de dados de internet, pois, nem todos os aparelhos celulares comportavam acesso aos ambientes virtuais de aprendizagem (AVA) e computadores, eram exceção.

Contudo, os estudantes que conseguiram ter acesso, tiveram a oportunidade de desfrutar de uma aprendizagem diversificada por meio dos jogos e da ludicidade impressa na maior parte das aulas.

\section{CONSIDERAÇÕES FINAIS}

Diante do trabalho realizado com os estudantes foi possível notar um engajamento e protagonismo estudantil nas aulas de Geografia. Foi possível notar também que os estudantes passaram a ser mais presentes e participativos, demonstravam estar motivados a participar das aulas diante da aprendizagem divertida proporcionada pelo momento do jogo durante a aula, o que também contribuiu para ficarem mais atentos aos conteúdos abordados e encorajados a tirar dúvidas.

Ou seja, de modo geral, o jogo além de deixar as aulas divertidas para professor e estudantes (e pais), também ajudou os estudantes a ficarem menos inibidos, mais protagonistas, mais encorajados, mais engajados e continuar a estudar em meio as dificuldades da pandemia.

Pode-se perceber também que o desafio de ensinar em meio a pandemia é maior do que a simples transmissão de conhecimentos científicos, mas, é preciso lidar com as situações socioemocionais que afetam os estudantes. E, promover espaços de acolhimento e alegria nas aulas, reforça a ideia de pertencimento e motivação a escola, que passa a fazer novamente sentido no meio digital.

\section{AGRADECIMENTOS}

Os agradecimentos vão em especial para meus estudantes do $7^{\circ}$ ano de 2020 da Escola Municipal São Cristóvão que participaram ativamente das atividades descritas. À professora e 
amiga da Rede Municipal de Ensino do Recife, Fernanda Carneiro que me apresentou a ferramenta Wordwall e explicou sobre seu uso e possibilidades no ensino.

\section{REFERÊNCIAS}

ALVES, Lynn Rosalina Gama; MINHO, Marcelle Rose da Silva; DINIZ, Marcelo Vera Cruz. Gamificação: diálogos com a educação. In: FADEL, Luciane Maria et al. (Org.). Gamificação na educação. São Paulo: Pimenta Cultural, 2014, p. 74-97.

BACICH, Lilian; MORAN, José (Org.). Metodologias ativas para uma educação inovadora: uma abordagem téorico-prática. Porto Alegre: Penso, 2018.

FREIRE, P. Pedagogia da autonomia: saberes necessários a pratica educativa. 31 ed. São Paulo: Paz e Terra, 2007.

LIMA, Janiara Almeida Pinheiro (Org.). Geografia e prática docente remota: relatos durante a pandemia da covid-19. Olinda: Livro Rápido, 2020.

LUCKESI, C. L. N. Tecnologia Educacional. Rio de Janeiro, 1994.

MENDONÇA, Helena Andrade. Construção de Jogos e uso da Realidade Aumentada em Espaços de criação digital na educação básica. In: BACICH, Lilian; MORAN, José (Org.). Metodologias ativas para uma educação inovadora: uma abordagem téorico-prática. Porto Alegre: Penso, 2018, p.106-127.

MORAES, Jerusa Vilhena; CASTELLAR, Sonia Maria Vanzella. Metodologias ativas para o ensino de Geografia: um estudo centrado em jogos. Revista Electrónica de Enseñanza de las

Ciencias, 2018, Vol. 17, $\mathrm{N}^{\mathrm{O}} \quad 2, \quad 422-436 . \quad$ Disponível $\quad \mathrm{em}:<$ http://reec.uvigo.es/volumenes/volumen17/REEC 17_2_07_ex1324.pdf > . Acesso em: $12 \mathrm{fev}$. 2021.

RECURSOS. Wordwall. Disponível em: $<$ https://wordwall.net/pt/features $>$. Acesso em: 16 ago. 2020.

SANTOS, S. M. P. A ludicidade como ciência. Petrópolis, RJ: Vozes, 2001.

SENA, Samara; SCHMIEGELOW, Sarah Schmithausen; PRADO, Gladys M. B. C.; SOUSA, Richard Perassi Luiz; FIALHO, Francisco Antonio Pereira. Aprendizagem baseada em jogos digitais: a contribuição dos jogos epistêmicos na geração de novos conhecimentos. Novas Tecnologias na Educação. CINTED-UFRGS. V. $14 \mathrm{~N}^{\mathrm{o}}$ 1, julho, 2016. Disponível em: $<$ https://www.seer.ufrgs.br/renote/article/viewFile/67323/38417>. Acesso em: 12 fev. 2021.

SILVA, Dayane Fernandes. Ludicidade no processo de aprendizagem: uma análise sob a visão dos educadores infantis. TCC. UFPB, 2016. Disponível em:< https://repositorio.ufpb.br/jspui/handle/123456789/1808?locale $=\mathrm{pt}$ BR $>$. Acesso em: 2 fev. 2021. 